\title{
EXPANDING CONSERVATION THROUGH NEW TOOLS AND INNOVATIONS
}

\section{ENVIRONMENT PROGRAM REFLECTION}

The S. D. Bechtel, Jr. Foundation envisions a California that manages, stewards, and conserves its water and land to support a resilient environment and healthy communities. As the Foundation approaches conclusion in 2020, staff are documenting strategies from priority program portfolios. Access the series of Foundation reflections at sdbjrfoundation.org.

\section{OVERVIEW}

The S. D. Bechtel Foundation land portfolio was designed to strengthen conservation organizations, statewide systems, and policies that ensure the long-term vitality of California's wildlife and ecosystems.

California has a long and storied history of leading on conservation issues, including creating some of the world's first state and national parks. Nevertheless, as the Foundation board decided in 2009 to spend down all assets, it was evident that supporting the state's wildlife and ecosystems required new approaches and a scale of conservation that would include but extend well beyond protected lands and parks.

The Foundation's ambitions were bolstered by experience gained through its longstanding commitment to ensure that California wetlands were sufficient to sustain migratory bird populations. Years of program investment had demonstrated how tools and policies could help protect a globally important conservation target while also advancing innovation

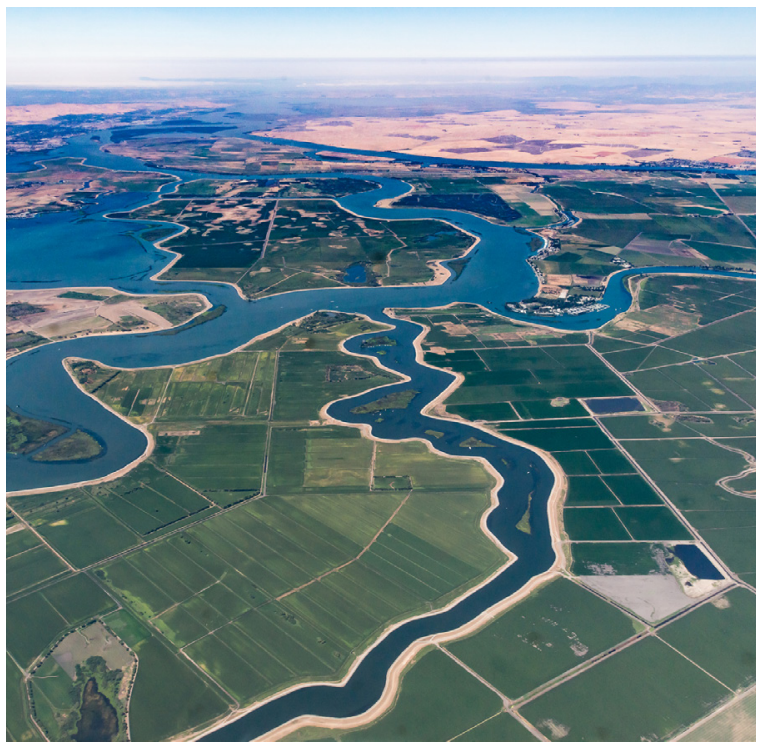
in the conservation field.

By 2009, grantees in the Foundation's Environment Program were achieving success with incentivizing private landowners to create habitat for migratory birds. The spend-down decision brought funding that enabled larger investments to build on the kinds of innovative approaches these grantee organizations were activating.

Foundation staff were clear-eyed in knowing there was no silver bullet to achieve the large-scale successes needed to conserve California's remarkable wildlife and biodiversity. The Environment team supported the field in experimenting with new approaches in hopes that the most promising innovations could be demonstrated, put into policy, and institutionalized.

Improving statewide conservation systems is hard in any scenario, and especially so in a time-limited circumstance. The Foundation's intent to conclude operations, with an end date ultimately set for 2020, meant there might be limited chances for emerging innovations to align with political will and receptivity to new policy. Nevertheless, with a tolerance for risk, the Foundation made significant investments to help the field develop new approaches that could carry conservation efforts forward even as the Foundation ended its role as a major funder in California. 


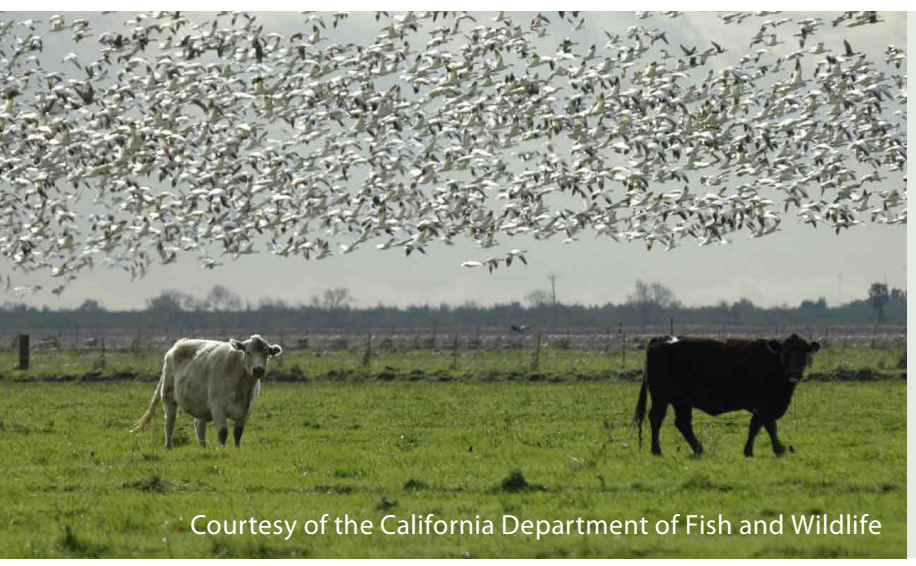

The land portfolio was anchored in the premise that landscapes are a complex mosaic of farmlands, communities, parks, wildlife habitat, and much more. The goal is for people and nature to thrive by taking all of these values into account, understanding and balancing trade-offs, and finding ways to simultaneously achieve multiple benefits - for example, supporting farms to produce food and habitat.

\section{MAKING CONSERVATION PART OF EVERYONE'S BUSINESS}

The Foundation shaped its land portfolio and pursued statewide solutions through two interconnected strategies:

Supporting policy and systems change. Investments were designed to integrate wildlife and habitat conservation into land-use planning, flood protection, infrastructure building, and other systems. The Foundation supported improved public policies as well as development of tools to help people bring conservation into their work in new ways.

Creating incentives for private landowners. Investments were designed to demonstrate new models that align incentives in ways that would remove barriers to conservation. The Foundation supported innovative programs that could incent farmers, ranchers, and other landowners to protect wildlife and create habitat on their lands even as they kept those lands in production.

Each strategy is further described on subsequent pages, followed by the Foundation's perspective on the importance of integrative approaches to meeting the needs of nature and people. A concluding section points to opportunities for funders and policymakers seeking to expand conservation.

\section{PROGRESS HIGHLIGHTS}

Through substantial investments across its spend-down years, the Foundation was instrumental in introducing and demonstrating innovative conservation tools and launching promising models for aligning incentives and removing barriers to conservation. Highlights include:

$\checkmark$ Regional Conservation Investment Strategies are active across California. This new statewide program provides a means to improve large-scale conservation results by engaging multi-sector stakeholders in implementing regional conservation priorities. Ten areas around the state have launched Regional Conservation Investment Strategies that collectively cover 10 million acres $-10 \%$ of California.

$\checkmark$ Expanded and enhanced habitat is available to migratory birds. The Migratory Bird Conservation Partnership helps ensure that as much as 100,000+ acres of habitat are available annually for migratory birds in California, including on private farms.

\section{$\checkmark$ New tools and approaches are integrating conservation into the ways people do} business. County land-use planning departments are using new tools to integrate conservation into their processes, and flood control agencies are working with farmers to create habitat for endangered species. 


\section{SUPPORTING POLICY AND SYSTEMS CHANGE}

California's continued growth has reached a critical point in the need to protect ecosystems and wildlife habitats. The infrastructure required to support key statewide goals - including renewable energy generation, transportation improvements, and flood protection - has enormous projected impacts on wildlife and their habitats. The tools available to avoid, minimize, and mitigate those impacts have proven increasingly inflexible and ineffective in addressing both conservation and infrastructure needs.

To respond to this situation, the Foundation worked with a core group of partners and in 2016 helped create Regional Conservation Investment Strategies (RCIS), a major new program at the California Department of Fish and Wildlife. This approach can improve large-scale conservation results by:

- Identifying regional conservation priorities and targeting public conservation expenditures to achieve those priorities.

- Guiding infrastructure agencies to avoid habitat impacts, including informing siting decisions that can avoid and minimize impacts to key species and habitats.

- Creating a functional system of advance habitat mitigation - allowing public agencies to invest in conservation prior to impacts that are created from new infrastructure and other development, and facilitating all parties to work in a more coordinated and effective fashion.

The program emerged from collaboration among staff in Governor Jerry Brown's administration, leadership at the California Department of Fish and Wildlife, conservation experts, and the Foundation. These partners brought together the political will, expertise, and flexible resources to demonstrate the approach - all ingredients that rarely combine but are essential to scaling innovation in systems. The Foundation provided proof-of-concept funding to initiate five pilot RCIS projects and coordinate statewide efforts. Philanthropic support made it possible to engage experts and nonprofit stakeholders so that local and state agencies could work with partners who bring the deep understanding, insights, and flexibility needed to craft a new approach. Through RCIS pilots, stakeholders explored a variety of approaches for using this new tool in a range of geographic and political contexts.

Breaking down silos is hard, and it is very complex to integrate conservation into other large systems such as flood control and highway building. Expansion of the RCIS program has proven slower than hoped due to the time needed to put in place processes required by a new state policy and to develop best practices for application of the RCIS construct. There is reason to be optimistic about the relevance and lasting value of this approach: Regions beyond the initial pilots of RCIS efforts have begun implementation without the benefit of philanthropic support.

By 2020, Regional Conservation Investment Strategies were underway in 10 regions that encompass over 10 million acres, collectively composing $10 \%$ of the state. This $10 \times 10 \times 10$ statistic illustrates the potential that counties and transportation planners see in the RCIS program as a mechanism to coordinate conservation investments and infrastructure projects in ways that lead to improved project implementation and conservation outcomes. 


\section{LEVEE MAINTENANCE, GIANT GARTER SNAKES, AND FARMLAND IN COLUSA COUNTY}

Regional Conservation Investment Strategies can address a variety of needs, including engaging private landowners to create habitat for wildlife. For example, the Foundation funded an experiment in response to a dilemma affecting the region around Colusa County in the northern Central Valley of California. The local irrigation district needed to conduct seasonal levee maintenance to prevent flooding from the Sacramento River. However, it couldn't readily secure necessary permits from wildlife agencies to do this work because of the presence of giant garter snakes and other endangered species.

Partners began developing a Regional Conservation Investment Strategy with the idea that it would eventually allow farm owners to earn credits for creating seasonal giant garter snake habitat on their properties, and then sell the credits to the irrigation district. In effect, the local agency could pay farmers to grow habitat to replace the habitat that might be affected during levee maintenance. In return, the irrigation district would earn habitat credits it could use to obtain permits from the Department of Fish and Wildlife to conduct levee maintenance. As a result, the region and its communities would gain flood protection while wildlife habitat is enhanced.

\section{CREATING INCENTIVES FOR PRIVATE LANDOWNERS}

The Foundation's significant investment in the Migratory Bird Conservation Partnership - launched in 2008 and comprising Audubon California, The Nature Conservancy, and Point Blue Conservation Science - tested approaches that combine incentives for private landowners with improved policies. The partnership harnessed U.S. Farm Bill funding and developed innovative new programs to ensure that as much as 100,000 acres of habitat were annually available for migratory birds in California. Partners' efforts paid dividends for California during the drought years beginning in 2013.

Building on these productive efforts to incentivize owners of working lands to provide seasonal habitat, the Foundation and its partners explored a new approach to deliver just-in-time habitat. "Dynamic conservation" makes use of emergent technologies and big data to better understand ecological systems, enabling conservationists to supply high-quality, cost-effective habitat in a flexible and adaptive manner.

Creating temporary "pop-up wetlands" for migratory birds shows the power of this approach. Wildlife refuges and other permanently protected lands provide essential habitat for migratory birds, especially in California's Central Valley, but are not sufficient to meet the needs of tens of millions of birds traveling along the continuously shifting landscapes of the Pacific Flyway spanning Alaska to Patagonia. Migratory birds need hundreds of thousands of acres of habitat beyond what can be provided by permanently protected areas, and the cost of acquiring and protecting this amount of additional habitat is prohibitive.

In 2013, The Nature Conservancy launched BirdReturns, a pilot program to efficiently and fairly compensate landowners for creating needed seasonal habitat through bird-friendly agricultural practices. The pilot successfully employed a reverse-auction model, with landowners bidding for the price at which they would create habitat for migratory birds. 
The Nature Conservancy has partnered with a network of farmers to create tens of thousands of acres of high-quality seasonal habitat for migratory birds, targeting times when the birds are in critical need of additional habitat. Under the program, rice growers are paid a fee to temporarily flood their fields, and these flooded fields attract upward of 30 times more shorebirds than non-participating fields. More than 180,000 waterbirds representing 50 species have been counted on program fields during a single fall season.

With support from the Foundation, BirdReturns quickly demonstrated the efficacy and potential of a more dynamic approach to meeting the needs of nature in a complex, human-dominated world. To build on early successes, the Foundation supported research and grantee initiatives to prove out the concept in a variety of settings beyond the needs of migratory birds, including salmon-rearing habitat on floodplains and endangered species in the Central Valley like Swainson's Hawk.

These efforts integrated closely with the Foundation's water portfolio and created synergies across its Environment Program.

\section{INCENTIVES PROVE VITAL TO BIRD HABITATS}

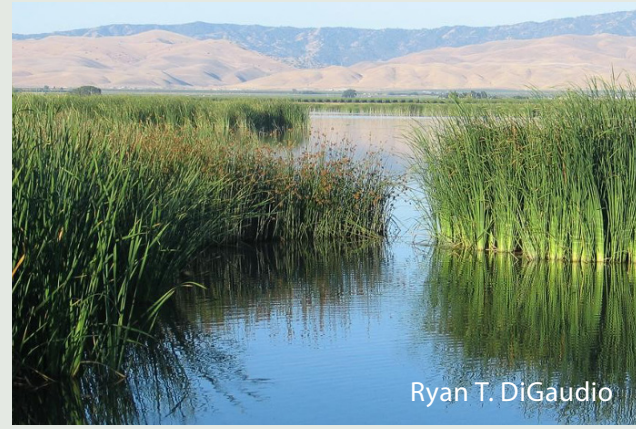

The drought years 2013 to 2015 were the most severe in more than 100 years of reported history for California's Central Valley, significantly shrinking the habitat used by waterbirds. Without environmental groups, landowners, and state agencies working together through incentive programs, the harm would have been much worse.

Research scientists from Point Blue Conservation Science and The Nature Conservancy, two

Foundation grantees, used satellite imagery to show that the drought reduced the amount of waterbird habitat on flooded agricultural lands and wetlands by $30 \%$ to $80 \%$, with the greatest losses in the southern Central Valley.

They also documented how incentives proved vital during this period. Through BirdReturns, the Waterbird Habitat Enhancement Program, and other incentive programs supported by the Foundation, farmers are paid to flood rice or other crop fields that provide birds with temporary habitat when and where they need it, essentially creating pop-up wetlands.

The two programs named above accounted for up to $61 \%$ of habitat available to waterbirds on fall days during 2013 to 2015 . On some winter days, up to $100 \%$ of available habitat came from these programs. This study demonstrated that the ability to flood fields and create habitats at key moments provides a much-needed means to sustain waterbirds in times of severe drought, a phenomenon that climate scientists project may become more frequent over the next century. 


\section{PATH FORWARD: INTEGRATIVE APPROACHES CAN MEET THE NEEDS OF PEOPLE AND NATURE}

The strategies described above supported the land portfolio's overall aim to help build the tools, develop the mindsets, and put in place the policies required to steward ecosystem health while meeting a complex set of needs. On any given regional landscape, people are trying to produce food, preserve nature and wildlife, guarantee adequate drinking water, prevent devastating wildfires, reduce carbon emissions, and secure many other goals. Pursuing one of these values in isolation often collides with others, frequently in unintended ways.

Given these challenges inherent to conservation, Foundation staff worked alongside leaders in a wide range of California communities to deepen shared understanding of the need to manage landscapes for multiple benefits simultaneously. This "integrative" approach focuses on identifying trade-offs and pursuing optimal results that serve both human and natural ecosystems.

Managing California forests for resilience has emerged as a good example of the need for this integrative approach. Following devastating droughts and wildfires, the Foundation seeded partnerships and deep policy analysis to explore restoring forests in ways that decrease wildfire risk and carbon emissions while increasing community jobs and forest health.

Additional investments also supported a variety of innovations that are contributing to catalyzing this kind of multi-benefit conservation approach across landscapes. For example, the Foundation invested in:

- Supporting partner biologists working to improve rangeland stewardship and water supply.

- Enhancing the network of Resource Conservation Districts that support conservation on farms and range lands.

- Creating new decision-support tools that help county land use planners analyze multiple benefits on a landscape.

Developing a diverse suite of innovative tools and approaches was in part opportunistic and in part purposeful - pursued with an eye to crafting a multifaceted toolbox that can address complex problems on mosaic landscapes.

Although much remains to be done, the Foundation used its spend down as an opportunity to make big bets and invest in the tools and experiments that regions need to embrace this integrative approach. As a result, key organizations, policies, and systems are stronger in ways that can support continuing innovation and greater results going forward.

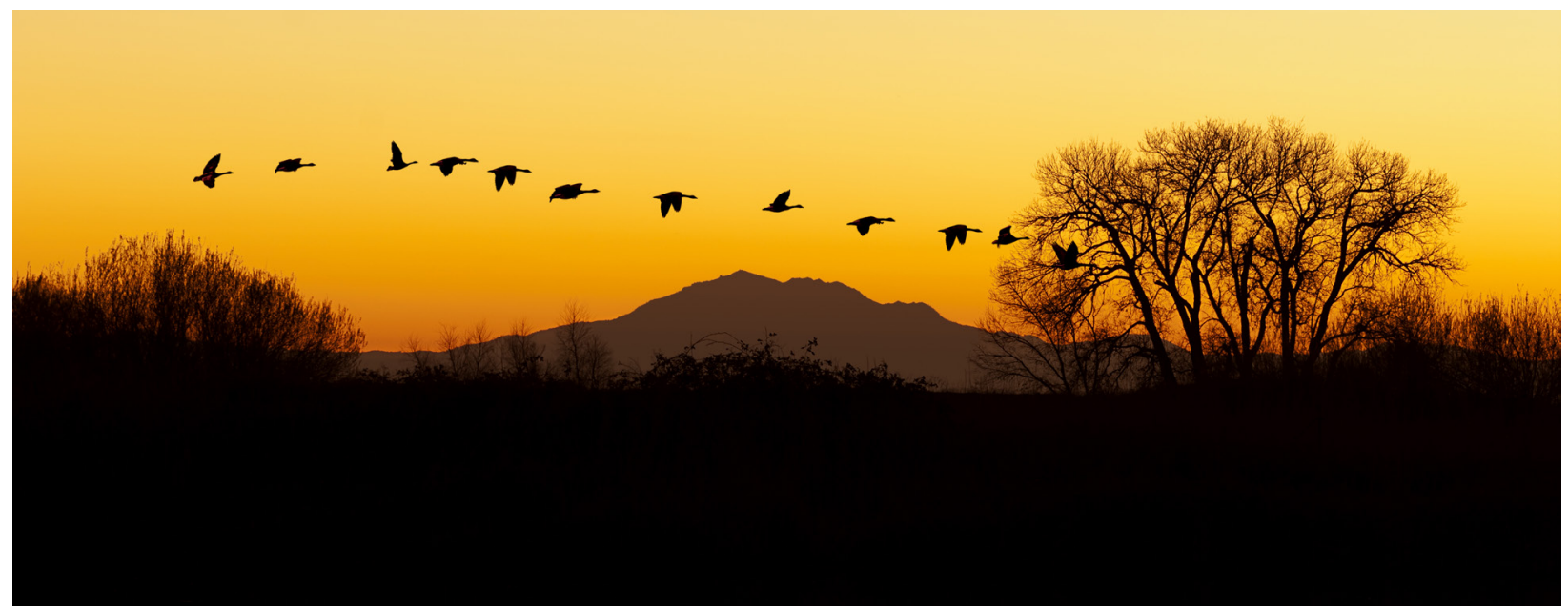




\section{OPPORTUNITIES FOR FUNDERS AND POLICYMAKERS}

This reflection is written midway through 2020, a time when demands for just public systems, changing policy priorities, and pressure on funding sources reinforce the importance of integrative, adaptive approaches that expand conservation. Foundation staff spotlight the following opportunities for funders and policymakers.

1. Conservation can be part of everyone's business. Public agencies increasingly recognize the need to integrate nature into solutions for the complex issues they work on. For example, flood control agencies, transportation planners, and other key players want to incorporate wildlife and habitat goals into their processes. This involves improving public policies as well as developing tools to help people integrate conservation in new ways. Philanthropy can catalyze innovation in public agencies and systems, including helping individual agencies access the expertise and supports they need to pursue significant change, and enabling partnerships with communities and private landowners that can create large-scale impact. These efforts call for sustained, adaptive engagement by funders - and can lead to bold advances.

2. Incentives can bring private landowners into conservation. The approaches for incenting farmers, foresters, and others to integrate conservation into their practices are still evolving. Improvements to public funding programs can make these incentives more effective in conserving natural systems and more appealing to private landowners. There is need to explore how incentives can take a more holistic approach to private landowner operations and target the overall resiliency of the complete system, versus trying to incentivize a single benefit - such as carbon or biodiversity - in isolation.

3. This is the time to advance integrative solutions. Decision-support technology as well as shifting mindsets are leading to better approaches to regional land use, water management, energy development, and more. Leaders in diverse public sectors are finding ways to optimize a variety of societal needs within a landscape, balancing trade-offs and finding solutions that carry multiple benefits. Addressing California's critical issues - including reducing wildfire, securing groundwater, adapting to climate change, and preserving wildlife - requires investment and policy supports for multi-benefit approaches.

4. Climate change demands flexible approaches. Climate change is creating tremendous variability, suggesting the need to move from managing landscapes as fixed to a much more dynamic paradigm. Investments are needed to explore approaches that recognize the inherent interplay of ecological and human systems, and seek flexible, adaptive solutions to meet conservation targets and be responsive to these systems' changing conditions. Public funding, shared goals, and mindsets need to evolve to bring these necessary innovations to scale.

\section{RELATED READING}

"Migration Moneyball - California." How data science and innovative economics are helping The Nature Conservancy build a brighter future for migratory birds.

Migratory Bird Conservation Partnership. A collaboration between Audubon California, The Nature Conservancy, and Point Blue Conservation Science.

Regional Conservation Investment Strategies Program. California Department of Fish and Wildlife.

Bay Area Greenprint. A data resource for those building natural resource conservation into policies and plans. Advancing Durable and Relevant Protected Lands. Foundation staff reflection. 